\title{
Tuning Conformational H-Bonding Arrays in Aromatic/Alicyclic Polythiourea toward High Energy-Storable Dielectric Material
}

\author{
Yang Feng, ${ }^{\dagger \neq}$ Yui Hasegawa, ${ }^{\ddagger}$ Takeo Suga, ${ }^{*}{ }^{*}$ Hiroyuki Nishide, ${ }^{*}+\infty$ Liuqing Yang, $^{\dagger}$ George Chen, ${ }^{\dagger}$ \\ and Shengtao $\mathrm{Li}^{*}, \dagger$ \\ †State Key Laboratory of Electrical Insulation and Power Equipment, School of Electrical Engineering, Xi'an Jiaotong University, \\ Xi'an 710049, Shaanxi, China \\ ${ }^{\ddagger}$ Department of Applied Chemistry and Research Institute of Science and Engineering, Waseda University, Tokyo 169-8555, Tokyo, \\ Japan
}

\section{Supporting Information}

ABSTRACT: Polythioureas (PTUs) have been investigated as a dielectric material for an energy-storable capacitor in both experimental and computational approaches. However, the effect of dipolar polarization, closely associated with conformational H-bonding arrays, on dielectric properties under the operating frequency has never been studied in PTUs. Here, a series of PTUs with different spacers and additional dipoles are synthesized to explore the influence of conformations in thiourea units on their dielectric properties. The additional dipolar substituent $(-\mathrm{COOH})$ contributes to a high dielectric

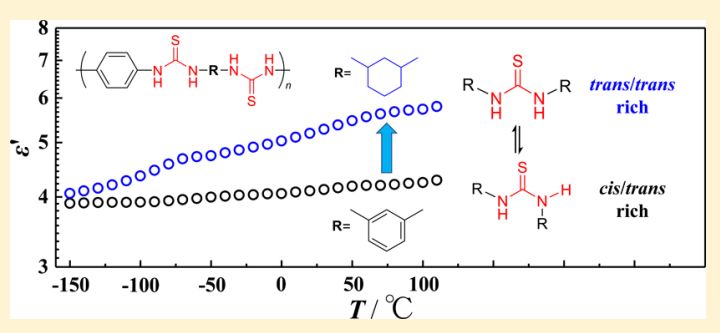
constant, while accompanying a remarkable dielectric loss. Alternatively, a random copolymer is prepared to adjust the $-\mathrm{COOH}$ content, which displays a high dielectric constant and a suppressed dielectric loss. However, it requires strict control of the segmental ratio to meet the energy-storage demand. A neat alicyclic PTU with a flexible cyclohexyl spacer also exhibited a high dielectric constant and a low dielectric loss because of its rich trans/trans conformation, which brings about an increasing effective dipole moment per unit volume. Meanwhile, it retains high breakdown strength, thus leading to high electric energy density $\left(U_{\mathrm{e}} \approx 10 \mathrm{~J} / \mathrm{cm}^{3}\right)$. These results suggest that tuning conformational $\mathrm{H}$-bonding arrays based on molecular design is a more effective way to improve the dielectric properties of PTUs toward a very high energy storable material.

\section{INTRODUCTION}

Dielectric capacitors with high electric energy density have been developed and investigated for a number of modern flexible electronic devices and large-scale electrical power grid systems. ${ }^{1-7}$ With advance in miniaturization of these devices and systems, it is highly desirable to improve the electric energy density of the dielectric materials. The electric energy density $\left(U_{\mathrm{e}}\right)$ of the material can be obtained using $U_{\mathrm{e}}=$ $0.5 \varepsilon_{0} \varepsilon_{\mathrm{r}} E_{\mathrm{b}}^{2}$, where $\varepsilon_{\mathrm{r}}$ is dielectric constant, that is, electric field independent, and $E_{\mathrm{b}}$ is the breakdown strength. ${ }^{2,3,5}$ Recent years have witnessed extensive efforts to address this issue through improving these two key performance parameters to enhance the electric energy density of capacitors. The nonpolar biaxially oriented polypropylene film with a high breakdown strength of about $700 \mathrm{MV} / \mathrm{m}$ has been commercially utilized, but its electric energy density is limited to below $5 \mathrm{~J} / \mathrm{cm}^{3}$, owing to its intrinsic low dielectric constant $\left(\varepsilon_{\mathrm{r}}=\right.$ ca. 2.2$){ }^{8}$ Ferroelectric polymers, such as poly(vinylidene fluoride)-based copolymers, demonstrate a high permittivity $\left(\varepsilon_{\mathrm{r}}>50\right)$ and a high electric energy density $\left(>25 \mathrm{~J} / \mathrm{cm}^{3}\right)$. Nevertheless, it is still challenging to apply them to capacitors because of the obvious ferroelectric hysteresis losses at high field and high temperatures. ${ }^{9-11}$

Other polar polymers containing cyano, ${ }^{12,13}$ sulfone, ${ }^{14,15}$ urea, and thiourea moieties ${ }^{16,17}$ have been also explored to improve the dielectric constant. Among them, polythiourea (PTU) and polyurea (PU) with H-bonding showed superior dielectric properties and electric energy density. ${ }^{18-21}$ Zhang, et al. studied the effect of nanostructure derived from metalinked PU on its dielectric constant and reported that the disordered phase exhibited a higher dielectric constant than ordered phases. ${ }^{17}$ They also tuned the dipolar density of aromatic PTUs to improve their properties and thus obtained one of the para-linked aromatic PTUs via microwave-assisted polycondensation that exhibited high breakdown strength and high electric energy density. ${ }^{20}$ Besides the empirical experimental approach, Ramprasad et al. also successfully proposed a rational codesign strategy and a data-driven fingerprinting method for designing dielectric polymers, where PTUs displayed excellent dielectric properties as well. ${ }^{21-23}$ Besides electronic and atomic polarizations, the orientation polarization of dipoles in polar polymers can also contribute to the dielectric constant in the operating frequency below $10^{6} \mathrm{~Hz}$, which is closely related with their conformations. However, conformational features and $\mathrm{H}$-bonding interactions in PTUs have been ignored in both experiments and the above-

Received: August 24, 2019

Revised: October 25, 2019 
mentioned machine-learning (ML) methods. Hence, it is essential to detect these characteristics in PTUs, thus providing more details for ML models to make the dielectric prediction more precise.

In this report, we investigated the conformational features of thiourea units and detected their effect on dielectric properties for PTUs through incorporating different spacers and a functional polar substituent $(-\mathrm{COOH})$. Based on the previous reports, we can obtain that $\mathrm{H}$-bonding is important for the arrangement of polymer chains. ${ }^{24,25}$ Both PTU and PU prefer to form strong $\mathrm{H}$-bonding networks, linking the acceptor unit $(\mathrm{C}=\mathrm{O}$ or $\mathrm{C}=\mathrm{S})$ and two donor units $(\mathrm{N}-\mathrm{H})$. However, contrary to the linear $\mathrm{H}$-bonded urea array in semi-crystalline PU, PTU was likely to show the amorphous nature, originating from the less ordered, zigzag geometries of $\mathrm{H}$-bonded thiourea units and the coexisting cis/trans and trans/trans conformations. Recently, it was reported that aliphatic PTUs exhibited the zigzag $\mathrm{H}$-bonded array and rapidly exchangeable $\mathrm{H}$-bonded pairs. ${ }^{26}$ Such unique H-bonded array of thioureas can be considered to critically affect dielectric properties. It gave us a further understanding of the structure-property relationship in PTUs, providing a new material design perspective for high energy-storable dielectric polymers.

\section{RESULTS AND DISCUSSION}

2.1. Synthesis. A series of PTUs were synthesized via polyaddition polymerization between 1,4-phenylene diisothiocyanate and various diamines $\left(\mathrm{H}_{2} \mathrm{~N}-\mathrm{R}-\mathrm{NH}_{2}\right)$, as shown in Scheme 1. PTUs with rigid and flexible spacers were selected

Scheme 1. PTUs with Different Spacers and a Functional Polar Substituent

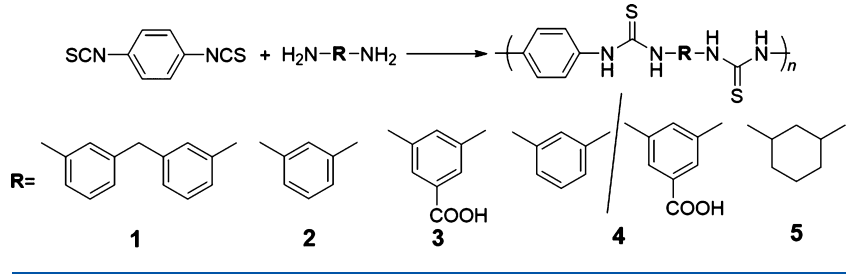

to elucidate the influence of these spacers on their conformations. In particular, m-linked diamines were selected to improve processability of the obtained PTUs. Chemical structures and the molecular weight $\left(M_{n}\right)$ of the obtained
PTUs were characterized by ${ }^{1} \mathrm{H}$ NMR spectroscopy and size exclusion chromatography, respectively, as shown in Table 1. The conformations and hydrogen bonding array geometries of thiourea units in PTUs (more detailed discussion appears in the following section) were carefully determined by Fourier transform infrared (FT-IR) spectra (as seen in Supporting Information), which were correlated with their dielectric properties.

2.2. Dielectric Property. Broadband dielectric spectra of PTUs were measured at various temperatures over the whole frequency range $10^{-1}$ to $10^{6} \mathrm{~Hz}$ to discuss the polarization characteristics in them. The dielectric constant of PTU 2 increased slightly with temperatures, as shown in Figure 1a. Even that, an obvious $\beta$ transition at around $-70{ }^{\circ} \mathrm{C}$, far below glass transition temperature, was observed at $10 \mathrm{~Hz}$ as shown in Figure 1b, which was assigned to the reorientation of dipolar thiourea units. It demonstrated that the $\beta$ transition in PTUs allowed dipolar thiourea to rotate along the applied electric field at room temperature at $10 \mathrm{~Hz}$, even in the glassy state. The same phenomenon was detected in PTU 1 in Figure S1. Based on the Frohlich model ${ }^{27,28}$

$$
\begin{aligned}
& \frac{\left(\varepsilon_{\mathrm{rs}}-\varepsilon_{\mathrm{r} \infty}\right)\left(2 \varepsilon_{\mathrm{rs}}+\varepsilon_{\mathrm{r} \infty}\right)}{\varepsilon_{\mathrm{rs}}\left(\varepsilon_{\mathrm{r} \infty}+2\right)^{2}}=\frac{N g u^{2}}{9 \varepsilon_{0} k T} \\
& \varepsilon_{\mathrm{r}} \propto N g u^{2} \\
& g \propto \cos \gamma
\end{aligned}
$$

where $\varepsilon_{\mathrm{rs}}, \varepsilon_{\mathrm{ro}}$, and $\varepsilon_{0}$ are the dielectric constants at low frequency, optical frequency, and in vacuum, respectively; $\gamma$ is the angle between dipole moment vectors, $N$ is the volumetric dipole density, $g$ is the orientation correlation function for short-range interactions between dipoles, which is proportional to the $\cos \gamma, u$ is the dipole moment, $k$ is the Boltzmann constant, and $T$ is the temperature. According to the Frohlich model, we can attain that the dielectric constant is proportional to the volumetric dipole density, the square of the dipole moment, and the orientation correlation function. Therefore, increasing the volumetric dipole density, permanent dipole moment, and the orientation correlation function are the three potential ways to improve the dielectric constant for materials. Compared with $\mathbf{1}$, the smaller spacer molecular size in $\mathbf{2}$ with a larger volumetric dipole density only led to a slightly increasing dielectric constant, corresponding to the previous result. ${ }^{20}$ It

\begin{tabular}{|c|c|c|c|c|c|c|c|c|c|}
\hline Polymer & $\begin{array}{c}\text { Spacer } \\
\text { Structure } \\
\mathbf{R}\end{array}$ & $\begin{array}{c}M_{\mathrm{n}}^{\text {a) }} \\
{[\mathrm{kg} / \mathrm{mol}]}\end{array}$ & $M_{\mathrm{w}} / M_{\mathrm{n}}$ & $\begin{array}{l}T_{\mathrm{g}}^{\mathrm{b})} \\
{\left[{ }^{\circ} \mathrm{C}\right]}\end{array}$ & $\begin{array}{l}\text { trans/trans } \\
\text { proportion }\end{array}$ & $\bar{\varepsilon}_{\mathrm{r}}^{\mathrm{c})}$ & $\begin{array}{c}\tan \delta^{\mathrm{d})} \\
{\left[\times 10^{-3}\right]}\end{array}$ & $\begin{array}{c}E_{\mathrm{b}}^{\mathrm{e})} \\
{[\mathrm{MV} / \mathrm{m}]}\end{array}$ & $\begin{array}{c}U_{\mathrm{e}}^{\mathrm{f})} \\
{\left[\mathrm{J} / \mathrm{cm}^{3}\right]}\end{array}$ \\
\hline 1 & & 26 & 2.0 & 108 & 0.54 & 4.0 & 3.7 & 653 & 7.5 \\
\hline 2 & & 28 & 2.3 & 110 & 0.51 & 4.1 & 3.1 & 885 & 14 \\
\hline 3 & & 26 & 2.2 & 78 & 0.57 & 7.9 & 56.3 & 51.0 & 0.091 \\
\hline 4 & & 24 & 1.8 & N/A & 0.57 & 5.3 & 7.2 & 607 & 8.6 \\
\hline 5 & & 29 & 2.1 & 107 & 0.72 & 5.1 & 8.7 & 652 & 9.6 \\
\hline
\end{tabular}
indicated that increasing the volumetric dipole density through

Table 1. Molecular Weight, Thermal Properties, and Dielectric Properties of PTUs

\footnotetext{
${ }^{a}$ Determined from SEC using DMF as the eluant. ${ }^{b}$ Determined from the second scan of DSC results. ${ }^{c}$ Dielectric constant $\left(\varepsilon_{\mathrm{r}}\right)$ was measured at room temperature and $10 \mathrm{~Hz} .{ }^{d}$ Dielectric loss $(\tan \delta)$ was measured at room temperature and $10 \mathrm{~Hz} .{ }^{e}$ Breakdown strength $\left(E_{\mathrm{b}}\right) .{ }^{f_{\text {Electric }}}$ energy density $\left(U_{\mathrm{e}}\right)$ was calculated from $U_{\mathrm{e}}=0.5 \varepsilon_{0} \varepsilon_{\mathrm{r}} E_{\mathrm{b}}^{2}$.
} 

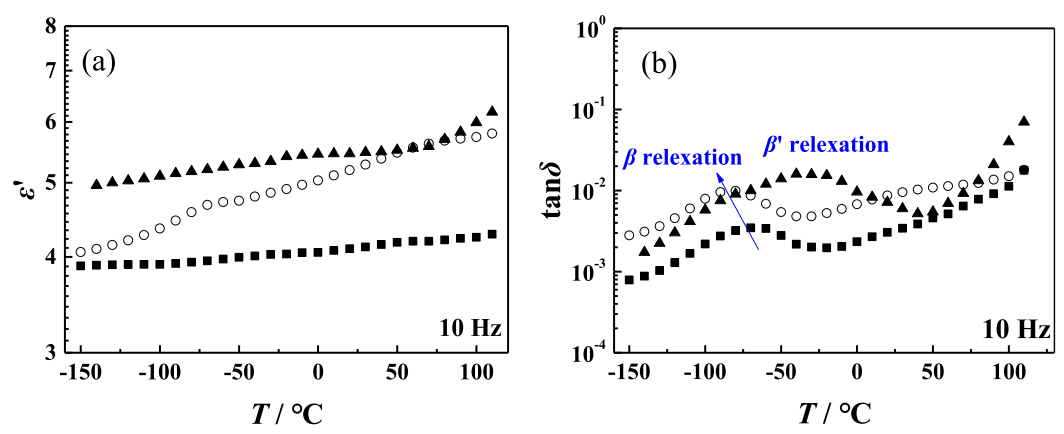

Figure 1. (a) Temperature dependence of the dielectric constant, (b) dielectric loss at $10 \mathrm{~Hz}$ of PTUs with different spacers and a carboxyl functional substituent at $20^{\circ} \mathrm{C}, 2(\boldsymbol{\square}), 4(\boldsymbol{\Delta})$, and $\mathbf{5}(\mathrm{O})$.
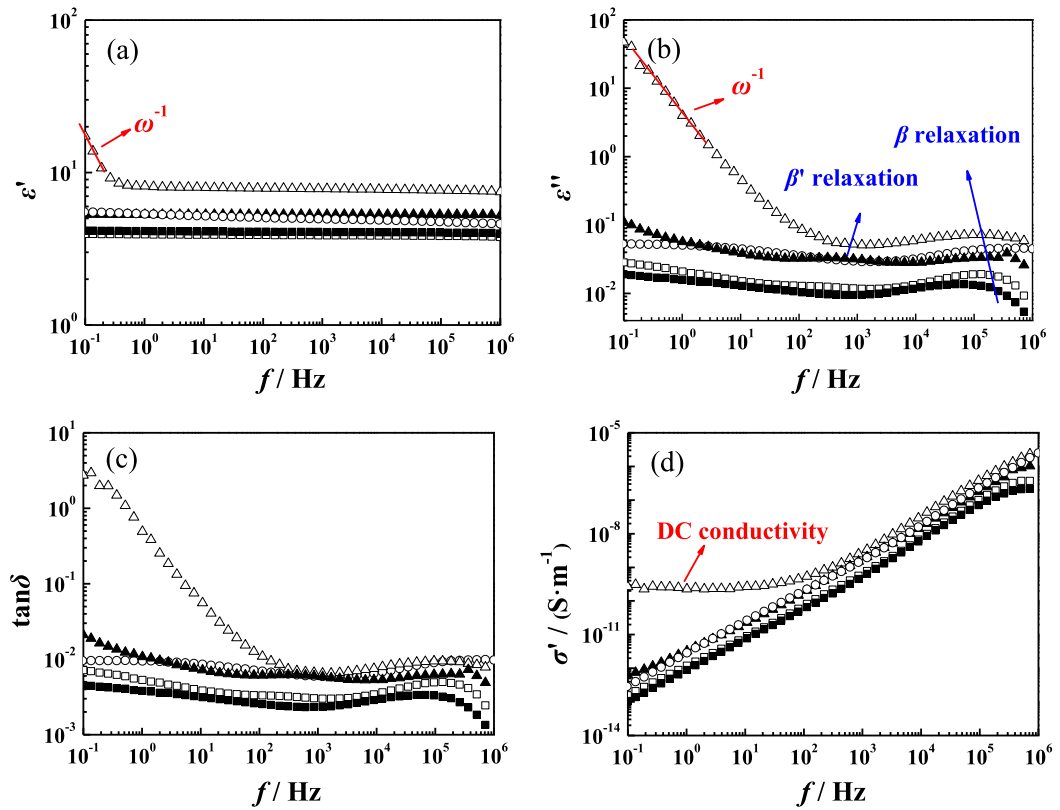

Figure 2. Frequency dependence of (a) the real part $\left(\varepsilon^{\prime}\right)$, (b) the imaginary part $\left(\varepsilon^{\prime \prime}\right)$ of the complex dielectric constant, (c) dielectric loss, and (d) conductivity of PTUs at $20^{\circ} \mathrm{C}, 1(\square), 2(\boldsymbol{\square}), 3(\triangle), \mathbf{4}(\boldsymbol{\Delta})$, and $\mathbf{5}(\mathrm{O})$.

modifying the molecular size is not an efficient method to improve the dielectric constant.

Here, we substituted the carboxyl polar group on m-position of the main chain phenylene, resulting in an increasing permanent dipole moment. The dielectric constant of 3 significantly increased $\left(\varepsilon_{\mathrm{r}} \approx 8\right)$ than that of nonsubstituted 2 and showed an exponential increase above $70{ }^{\circ} \mathrm{C}$, as shown in Figure S2a. Different from 1 and 2, the obtained temperature dependence of dielectric loss $(\tan \delta)$ for 3 in Figure S2b illustrated two obvious transitions from -150 to $110{ }^{\circ} \mathrm{C}$. The introduction of the pendant carboxyl group could enlarge the interchain space, which allowed more facile orientation of polar thiourea units in contrast to that in 2 . In addition, the carboxyl substituent, attaching to the main chain directly, can also reorient associated with the flip motion of the phenyl ring, which occurred at a higher temperature range compared with thiourea units. Hence, the $\beta$ relaxation and $\beta^{\prime}$ relaxation that occurred at around -80 and $-25{ }^{\circ} \mathrm{C}$ at $10 \mathrm{~Hz}$ were attributed to the reorientation of thiourea and carboxyl-phenyl units, respectively, resulting in an increase of the dielectric constant in comparison with 2 . However, the large $\varepsilon_{\mathrm{r}}$ for 3 was at the cost of dielectric loss owing to the reorientation of the carboxyl units and segmental motions at low frequency, especially at high temperatures, where the conduction became dominant and led to a sharp increase in the dielectric constant, as observed in Figure S2. It suggests that the excessive permanent dipole moment through introducing the polar substituent is not a promising way to design an energy-storable material. Alternatively, random copolymer 4 with a small number of polar substituents was designed to adjust both the advantages of 2 and 3. We prepared the random PTU copolymer 4 in the similar procedure as of the neat PTU, of which the molar ratio was PTU 2/PTU $3=10 / 3$. The dielectric constant of 4 increased to 5.3 because of the additional carboxyl dipoles (see in Table 1). It was further confirmed that additional dipoles could increase the dielectric constant in PTUs. The dielectric loss of 4 also displayed $\beta$ and $\beta^{\prime}$ relaxation processes, where the $\beta$ relaxation for the thiourea units occurred at lower temperatures in contrast to $\mathbf{2}$ because of their easier orientations. Additionally, the dielectric loss of $\mathbf{4}$ was suppressed in comparison with neat 3 , although it became prominent at high temperatures at $10 \mathrm{~Hz}$, as shown in Figure $1 b$.

It is necessary to improve the dielectric constant and maintain relative low dielectric loss over a wide range of temperatures. Apart from the volumetric dipole density and the permanent dipole moment, the orientation correlation function associated with the conformational H-bonded 

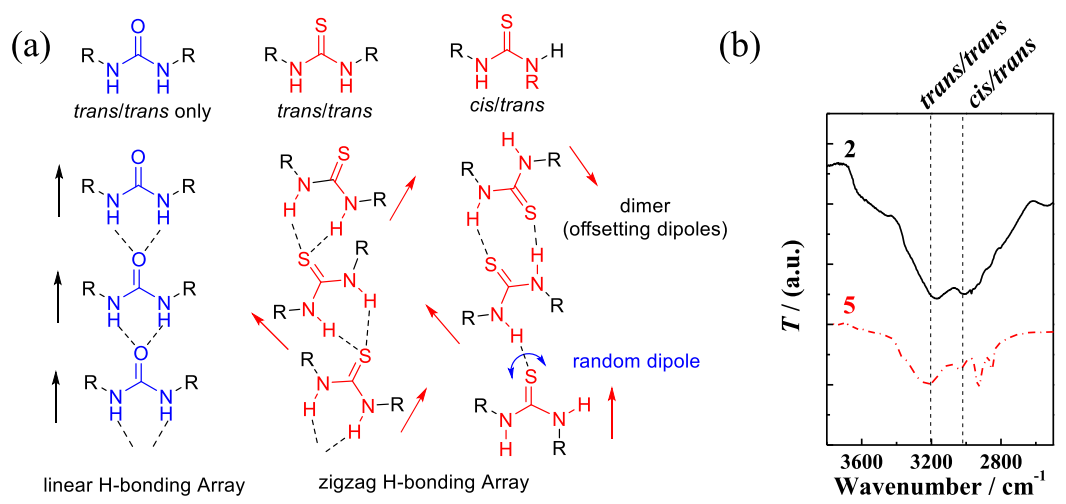

Figure 3. (a) Conformations and H-bonding motifs of urea and thiourea with the arrows representing the dipole moment and (b) IR spectra of PTU 2 (black line) and 5 (red line).

thiourea arrays, which determines the effective dipole moment per unit volume, is also another way to improve the dielectric constant. The previous result reported that the aliphatic PTU contains both trans/trans and cis/trans conformational $\mathrm{H}$ bonded pairs. $^{26}$ Therefore, a flexible cyclohexyl spacer was introduced into PTU 5 instead of the rigid $m$-phenylene spacer, without reducing the permanent dipole moment and volumetric dipole density at the same time.

The real part $\left(\varepsilon^{\prime}\right)$ and the imaginary part $\left(\varepsilon^{\prime \prime}\right)$ of the complex dielectric constant, dielectric loss $(\tan \delta)$, and conductivity $\left(\sigma^{\prime}\right)$ of all PTUs were also shown in Figure 2 as a function of frequency. The frequency-dependent dielectric spectroscopy showed that all PTUs displayed different dielectric responses. In contrast to the $\varepsilon^{\prime}$ of 3 showing an exponential growth when the frequency was approaching to $10^{-1} \mathrm{~Hz}$, the $\varepsilon^{\prime}$ of other PTUs increased slowly with decreasing frequency, as shown in Figure 2a. Also, the $\varepsilon^{\prime}$ of $\mathbf{5}$ was almost similar with that of 4 .

The $\varepsilon^{\prime \prime}$ of all PTUs in Figure 2b illustrated different dielectric relaxation processes. The $\beta$ relaxation, arising from the dipolar orientation of thiourea units, occurred in all PTUs above $10^{5} \mathrm{~Hz}$. An extra broad relaxation process, the $\beta^{\prime}$ relaxation in the mid-frequency-range, was detected in $\mathbf{3}$ and $\mathbf{4}$, originating from the reorientation of carboxyl-phenyl units. It indicated that the reorientation of thiourea units was easier than that of carboxyl-phenyl units. With further decreasing frequency, the $\varepsilon^{\prime \prime}$ of $\mathbf{3}$ showed an exponential growth, as descripted for $\varepsilon^{\prime}$. It demonstrated that dc conductivity became dominant at low frequencies, as verified by the conductivity results in Figure 2d, where an obvious plateau was observed in 3. Even though 3 exhibited an excellent dielectric constant, it led to a sharp increase of dielectric loss, as seen in Figure 2c. The dielectric loss and dc conductivity were suppressed in the copolymer 4 with a small number of polar carboxyl substituents, while at the cost of the dielectric constant. These results were consistent with the above-mentioned results.

Based on these results, we can obtain that 4 and 5 were two promising energy-storable dielectric materials. However, the origin of the high dielectric constant in $\mathbf{5}$ was still unclear. Therefore, the effect of conformations on the dielectric constant was explored for further understanding the structure-property relationship in PTU.

As discussed in earlier studies, ${ }^{25,26}$ FT-IR spectroscopy is a powerful tool to estimate the ratio of trans/trans and cis/trans conformations in PTUs by means of identifying H-bonding vibrations of $\mathrm{N}-\mathrm{H}$ stretching. IR spectra of both the asprepared powders and the casted film for PTUs were measured, and typical spectra were given in Figures S3 and S4. All the typical vibration broad bands of the $\mathrm{N}-\mathrm{H}$ stretching at around 3400, 3200, and $3000 \mathrm{~cm}^{-1}$ at film states red-shifted in comparison with the corresponding powders, indicating that the $\mathrm{H}$-bonding evolved during the film formation. The first one was the characteristic of the free $\mathrm{N}-\mathrm{H}$ without forming the $\mathrm{H}$-bonding, which diminished after film formation. The second one was assigned to the $\mathrm{N}-\mathrm{H}$ stretching vibration of nonlinear, zigzag $\mathrm{H}$-bonded thiourea arrays, representing the strained trans/trans conformation, which is contrary to PU that only adopted linear trans/trans conformation, as shown in Figure 3a. The last one was caused by the $\mathrm{N}-\mathrm{H}$ deformation vibration of $\mathrm{H}$-bonded thiourea dimers, derived from cis/trans conformation. The trans/trans and cis/trans conformations coexisted in all PTUs 1-5 because of the close energy gap between the two conformations, in accordance with the previous papers on the aliphatic PTU. ${ }^{26}$ Two conformation (trans/trans and cis/ trans) ratios in PTUs were estimated from the IR absorption peak, which depended on their primary polymer structures. More detailed descriptions about the calculating process of two conformation (trans/trans and cis/trans) ratios in the PTU are provided in Supporting Information. The IR spectra suggested that the trans/trans conformation was dominant in $\mathbf{5}$, while trans/trans conformation in $\mathbf{2}$ was almost equivalent to cis/ trans conformation in 2 (see Table 1 and Figure $3 \mathrm{~b}$ ). The alicyclic flexible spacer in PTU $\mathbf{5}$ preferably brought about more trans/trans conformations, where the proportion of trans/trans conformation in 5 was increased to 0.72 ( 0.51 for 2 as the control).

It is obviously shown in Figure 1a that PTU 5 with a flexible cyclohexyl spacer exhibited larger $\varepsilon_{\mathrm{r}}$ than 2 . The trans/trans conformation adopted a nonlinear (zigzag) H-bonded thiourea array and resulted in an increasing effective dipole moment per unit volume, whereas the cis/trans conformation was likely to form a thiourea dimer leading to a mutually offsetting dipole moments, as illustrated in Figure 2a. The variant dielectric constants for 5 and $2\left(20^{\circ} \mathrm{C}, 10 \mathrm{~Hz}\right)$ in Figure la can be ascribed to the difference in their trans/trans conformational proportion, suggesting the trans/trans conformation of thiourea units played a more important role on the dielectric constant.

While the large dielectric constant for $\mathbf{5}$ was comparable to the data in the previous report, ${ }^{17}$ the dielectric loss remained 
low even at high temperatures, as seen in Figure $1 \mathrm{~b}$. The same phenomenon was also observed in PTU $\mathbf{1}$ with a flexible methylene spacer. Even though the larger molecular size in $\mathbf{1}$ led to a reduction in volumetric dipole density in comparison with 2 , the dielectric constants of them were almost similar, where the more trans/trans conformation in $\mathbf{1}$ was positive for increasing the dielectric constant. These results demonstrated that flexible spacers and accompanying trans/trans conformation of zigzag H-bonded arrays between thiourea units played an important role in the increase of the dielectric constant.

Breakdown strengths of PTUs were also carried out at room temperature and analyzed by Weibull distribution, as shown in Figure S5. The breakdown strengths for PTUs were summarized in Table 1. X-ray diffraction (XRD) was performed in order to elucidate the factors for the excellent breakdown strength in PTUs. XRD profiles of PTUs in Figure S6 exhibited broad diffraction peaks at around $2 \theta=24^{\circ}$, typical of amorphous material. The nonlinear zigzag $\mathrm{H}$-bonded arrays in PTUs suppressed crystallization, originating from the mixture of trans/trans and cis/trans conformations. Randomly oriented thiourea derived from cis/trans conformation acted as defects into the zigzag H-bonded arrays, bringing about more random dipoles. These random dipoles in PTUs could act as strong scattering centers for conduction electrons to prevent the premature failure and thereby leading to high breakdown strength. Given these factors, we assume that more rigid spacers and the accompanying more random dipoles from the cis/trans conformation may improve the breakdown strength.

Based on the dielectric constant and breakdown strength, the corresponding electric energy densities of PTUs were calculated, as given in Table 1 . Among all PTUs, 2 displayed the highest electric energy density, $14 \mathrm{~J} / \mathrm{cm}^{3}$, because of its superior breakdown strength. On the other hand, the electric energy density of 3 remained low even though its higher dielectric constant, which was mainly ascribed to poor breakdown strength, resulting from its inferior film formability. The electric energy density, $8.6 \mathrm{~J} / \mathrm{cm}^{3}$, was attained in copolymer 4, about 100 times larger than that of 3 because its breakdown strength was significantly improved compared with neat PTU 3. PTU 5 exhibited a higher dielectric constant, while the decreasing cis/trans conformation in them decreased the number of random dipoles and reduced scattering centers for preventing conduction electrons, which led to the lower breakdown strength than 2. Comprehensively, the electric energy density of $\mathbf{5}$ was almost similar with that of copolymer 4.

Different from the dielectric constant, the inherent factor only depends on the material itself; it should be noted that the breakdown strength can be influenced by external factors. ${ }^{29,30}$ Hence, the dielectric constant is more preferred to be considered than breakdown strength in molecular design to improve the electric energy density of materials. Both copolymer 4 and PTU 5 with suitable molecular structures displayed a high dielectric constant and relatively low dielectric loss. PTU 5, as a neat polymer, was easy to be synthesized, while the ratio of two segments in the random copolymer 4 required strict control to meet the energy-storable demand because more carboxyl dipoles could bring about remarkable dielectric loss. It gives us an insight that tuning conformational $\mathrm{H}$-bonded thiourea arrays is a more promising way to improve the balanced dielectric properties and electric energy density for designing an energy-storable material.

\section{CONCLUSIONS}

In summary, the dielectric properties and electric energy density of PTUs can be improved through tailoring the conformational $\mathrm{H}$-bonding thiourea arrays by modification of their molecular structures. Both introducing moderate dipolar substituents and tuning conformations in PTUs are two promising ways toward high energy-storable dielectric materials. The latter one by preparing neat PTUs is more feasible than the former one by preparing the copolymer owing to its strict adjustment between two segments to meet the energy-storable demand. The co-existing trans/trans and cis/ trans conformations in PTUs, deriving from the spacer molecular design, play an important role on their dielectric constants and breakdown strengths. The nonlinear zigzag $\mathrm{H}$ bonding array based on trans/trans conformation-rich PTUs with flexible spacers enhances the dielectric constant because of the increasing effective dipole moment per unit volume. On the other hand, the cis/trans conformation-rich PTUs are likely to bring about more random dipoles that provides more scattering centers for conduction electrons to prevent the breakdown. Hence, tuning conformational $\mathrm{H}$-bonding thiourea arrays in PTUs is an effective method to design energy-storable dielectric materials. In addition, we should include the conformational effect into the $\mathrm{ML}$ model to refine the approximation from the emerging computational approaches.

\section{EXPERIMENTAL SECTION}

4.1. Materials. 1,4-Phenylene diisothiocyanate, 3,3'-diaminodiphenylmethane, 1,3-phenylenediamine, 3,5-diaminobenzoic acid, and 1,3-cyclohexanediamine were purchased from Tokyo Chemical Industry Co. Ltd, Tokyo, Japan.

4.2. Synthesis. All PTUs with different spacers and functional units were synthesized through polyaddition polymerization, as illustrated in Scheme 1. For example, 1,4-phenylene diisothiocyanate $(0.01 \mathrm{~mol})$ was dissolved in $20 \mathrm{~mL}$ of anhydrous $N, N$ dimethylformamide (DMF). Diamine $(0.01 \mathrm{~mol})$ was added and reacted at room temperature under a $\mathrm{N}_{2}$ atmosphere for $24 \mathrm{~h}$. The resulting mixture was slowly poured into methanol. The precipitate was collected by filtration. The crude powder was dissolved in DMF, reprecipitated into methanol, and dried under vacuum at $80{ }^{\circ} \mathrm{C}$ overnight to yield the corresponding polymer 1-5. 1: ${ }^{1} \mathrm{H}$ NMR (500 $\left.\mathrm{MHz}, \mathrm{DMSO}-d_{6}\right): \delta 9.71,9.70$ (d, $\left.4 \mathrm{H}, \mathrm{NH}\right), 7.42$ (s, $\left.4 \mathrm{H}, \mathrm{Ar} \mathrm{H}\right), 7.39$, 7.37 (d, 2H, Ar H), 7.31 (s, 2H, Ar H), 7.241 (t, J = 7.5 Hz, 2H; Ar $\mathrm{H}), 7.01,6.99$ (d, 2H, Ar H), $3.91\left(\mathrm{~s}, 2 \mathrm{H}, \mathrm{CH}_{2}\right) .2:{ }^{1} \mathrm{H}$ NMR $(500$ $\left.\mathrm{MHz}, \mathrm{DMSO}-d_{6}\right): \delta 9.85(\mathrm{~s}, 2 \mathrm{H}, \mathrm{NH}), 9.73(\mathrm{~s}, 2 \mathrm{H}, \mathrm{NH}), 7.70(\mathrm{~s}, 1 \mathrm{H}$, Ar H), 7.45 (s, 4H, Ar H), 7.30 (s, 3H, Ar H). 3: ${ }^{1} \mathrm{H}$ NMR (500 MHz, DMSO- $\left.d_{6}\right): \delta 9.99(\mathrm{~s}, 2 \mathrm{H}, \mathrm{NH}), 9.87(\mathrm{~s}, 2 \mathrm{H}, \mathrm{NH}), 7.95(\mathrm{~s}, 1 \mathrm{H}$, Ar H), 7.91 (s, 2H, Ar H), 7.47 (s, 4H, Ar H). 4: ${ }^{1} \mathrm{H}$ NMR (500 $\left.\mathrm{MHz}, \mathrm{DMSO}-d_{6}\right): \delta$ 9.73-10.01 (m, 5.2H, NH), $7.95(\mathrm{~s}, 0.3 \mathrm{H}, \mathrm{Ar}$ $\mathrm{H}), 7.87(\mathrm{~s}, 0.6 \mathrm{H}, \mathrm{Ar} \mathrm{H}), 7.69(\mathrm{~s}, 1 \mathrm{H}, \mathrm{Ar} \mathrm{H}), 7.44(\mathrm{~s}, 5.2 \mathrm{H}, \mathrm{Ar} \mathrm{H})$, $7.29(\mathrm{~s}, 3 \mathrm{H}, \mathrm{Ar} \mathrm{H}) .5$ : ${ }^{1} \mathrm{H}$ NMR $\left(500 \mathrm{MHz}, \mathrm{DMSO}-d_{6}\right): \delta 9.40(\mathrm{~s}$, $2 \mathrm{H}, \mathrm{NH}), 9.27$ (s, 2H, NH), 7.38 (s, 4H, Ar H), 7.44 (s, 1H, Ar H), $4.11(\mathrm{~s}, 3 \mathrm{H}, \mathrm{Ar} \mathrm{H})$.

4.3. Characterization. Chemical structures and the molecular weight $\left(M_{n}\right)$ of PTUs were characterized by ${ }^{1} \mathrm{H}$ NMR spectroscopy and size exclusion chromatography, respectively. The more detailed information was given in the Table 1 . The PTU films with the thickness of $5 \mu \mathrm{m}$ were prepared by casting from the DMF $(1 \mathrm{~g})$ solution of PTU $(10 \mathrm{mg})$ on a copper substrate, followed by solvent annealing at $80{ }^{\circ} \mathrm{C}$ for $6 \mathrm{~h}$ and thermal annealing at $100{ }^{\circ} \mathrm{C}$ for $5 \mathrm{~d}$ under vacuum. The copper substrate was immersed in isopropanol, washed by ultrasonic treatment for $15 \mathrm{~min}$, and further cleaned by ozone treatment prior to use. Homogeneous and ductile films were obtained by simple casting from DMF solutions.

Dielectric measurement was carried out by using an impedance analyzer (Solartron SI26096W) from -150 to $110{ }^{\circ} \mathrm{C}$ with 
frequencies of $10^{-1}$ to $10^{6} \mathrm{~Hz}$ at room temperature under $1 \mathrm{~V}$ applied voltage. The $\mathrm{dc}$ breakdown strength at room temperature was implemented by using an $\mathrm{HJC}-100 \mathrm{kV}$ instrument which was provided by the Jilin Huayang Instrument and Equipment Company. A brass spherical electrode $(\phi=25 \mathrm{~mm})$ was used for the breakdown test, and the experimental data were analyzed with Weibull distribution function. Glass transition temperature was determined by differential scanning calorimetry (DSC) (TA Instruments, Q-200) under the nitrogen atmosphere at a heating rate of $10{ }^{\circ} \mathrm{C} / \mathrm{min}$ at the temperature range from 10 to $180{ }^{\circ} \mathrm{C}$. The conformational $\mathrm{H}$ bonding thiourea arrays in PTUs were detected by using a JASCO FTIR-6100FV instrument with the attenuated total reflection mode. Moreover, $\mathrm{XRD}$ with $\mathrm{Co} \mathrm{K} \alpha$ radiation was also performed to characterize their molecular structures.

\section{ASSOCIATED CONTENT}

\section{S Supporting Information}

The Supporting Information is available free of charge on the ACS Publications website at DOI: 10.1021/acs.macromol.9b01785.

Broadband spectra, FT-IR spectra of PTU powders, and films, Weibull distribution of dc breakdown strength for PTU 1-5, and XRD spectra (PDF)

\section{AUTHOR INFORMATION}

\section{Corresponding Authors}

*E-mail: takeosuga@waseda.jp (T.S.).

*E-mail: nishide@waseda.jp (H.N.).

*E-mail: sli@mail.xjtu.edu.cn (S.L.).

\section{ORCID $\odot$}

Hiroyuki Nishide: 0000-0002-4036-4840

Shengtao Li: 0000-0002-1014-8004

\section{Author Contributions}

Y.F., T.S., H.N., and S.L. planned the experiment and performed the device design. Y.F. and Y.H. fabricated the samples. L.Y., G.C., and S.L. supplied the material. Y.F. and Y.H. performed the measurements, while Y.F., L.Y., and T.S. analyzed the data and wrote the manuscript with input from all authors. The manuscript was written through contributions of all authors. All authors have given approval to the final version of the manuscript.

\section{Notes}

The authors declare no competing financial interest.

\section{ACKNOWLEDGMENTS}

This research was partially supported by the 111 Project (no. B17036) from the Ministry of Education and State Ministration of Foreign Experts Affairs, China, and by a Grant-in-Aid for Scientific Research (no. 18H03921) from the MEXT, Japan. Y.F. acknowledges the support from the China Scholarship Council (no. 201606280068).

\section{REFERENCES}

(1) Huan, T. D.; Boggs, S.; Teyssedre, G.; Laurent, C.; Cakmak, M.; Kumar, S.; Ramprasad, R. Advanced Polymeric Dielectrics for High Energy Density Applications. Prog. Mater. Sci. 2016, 83, 236-269.

(2) Dang, Z.-M.; Yuan, J.-K.; Zha, J.-W.; Zhou, T.; Li, S.-T.; Hu, G.H. Fundamentals, Processes and Applications of High-Permittivity Polymer-Matrix Composites. Prog. Mater. Sci. 2012, 57, 660-723.

(3) Prateek; Thakur, V. K.; Gupta, R. K. Recent Progress on Ferroelectric Polymer-Based Nanocomposites for High Energy Density Capacitors: Synthesis, Dielectric Properties, and Future Aspects. Chem. Rev. 2016, 116, 4260-4317.
(4) Cheng, L.; Chi, X.; Yan, C.; Xie, D.; Liu, X.; Wen, Y.; Liu, W.; Li, $S$. Polypropylene Nanocomposite for Power Equipment: A Review. IET Nanodielectrics 2018, 1, 92-103.

(5) Dang, Z.-M.; Yuan, J.-K.; Yao, S.-H.; Liao, R.-J. Flexible Nanodielectric Materials with High Permittivity for Power Energy Storage. Adv. Mater. 2013, 25, 6334-6365.

(6) Choi, U. H.; Liang, S.; Chen, Q.; Runt, J.; Colby, R. H. Segmental Dynamics and Dielectric Constant of Polysiloxane Polar Copolymers as Plasticizers for Polymer Electrolytes. ACS Appl. Mater. Interfaces 2016, 8, 3215-3225.

(7) Ding, Y.; Pawlus, S.; Sokolov, A. P.; Douglas, J. F.; Karim, A.; Soles, C. L. Dielectric Spectroscopy Investigation of Relaxation in C60-Polyisoprene Nanocomposites. Macromolecules 2009, 42, 3201-3206.

(8) Mackey, M.; Schuele, D. E.; Zhu, L.; Flandin, L.; Wolak, M. A.; Shirk, J. S.; Hiltner, A.; Baer, E. Reduction of Dielectric Hysteresis in Multilayered Films via Nanoconfinement. Macromolecules 2012, 45, 1954-1962.

(9) Zhang, Q. M.; Bharti, V.; Zhao, X. Giant Electrostriction and Relaxor Ferroelectric Behavior in Electron-Irradiated Poly(vinylidene fluoride-trifluoroethylene) Copolymer. Science 1998, 280, 21012104.

(10) Chung, T. C.; Petchsuk, A. Synthesis and Properties of Ferroelectric Fluoroterpolymers with Curie Transition at Ambient Temperature. Macromolecules 2002, 35, 7678-7684.

(11) Xia, F.; Cheng, Z.-Y.; Xu, H. S.; Li, H. F.; Zhang, Q. M.; Kavarnos, G. J.; Ting, R. Y.; Abdul-Sadek, G.; Belfield, K. D. High Electromechanical Responses in a Poly(vinylidene fluoride-trifluoroethylene-chlorofluoroethylene) Terpolymer. Adv. Mater. 2002, 14, $1574-1577$

(12) Bendler, J. T.; Boyles, D. A.; Edmondson, C. A.; Filipova, T.; Fontanella, J. J.; Westgate, M. A.; Wintersgill, M. C. Dielectric Properties of Bisphenol A Polycarbonate and Its Tethered Nitrile Analogue. Macromolecules 2013, 46, 4024-4033.

(13) Treufeld, I.; Wang, D. H.; Kurish, B. A.; Tan, L.-S.; Zhu, L. Enhancing Electrical Energy Storage Using Polar Polyimides with Nitrile Groups Directly Attached to the Main Chain. J. Mater. Chem. A 2014, 2, 20683-20696.

(14) Wei, J.; Zhang, Z.; Tseng, J.-K.; Treufeld, I.; Liu, X.; Litt, M. H.; Zhu, L. Achieving High Dielectric Constant and Low Loss Property in a Dipolar Glass Polymer Containing Strongly Dipolar and Small-Sized Sulfone Groups. ACS Appl. Mater. Interfaces 2015, 7, 5248-5257.

(15) Wang, Y.; Huang, X.; Li, T.; Wang, Z.; Li, L.; Guo, X.; Jiang, P. Novel Crosslinkable High-k Copolymer Dielectrics for High-EnergyDensity Capacitors and Organic Field-effect Transistor Applications. J. Mater. Chem. A 2017, 5, 20737-20746.

(16) Dong, R.; Ranjan, V.; Nardelli, M. B.; Bernholc, J. Atomistic Simulations of Aromatic Polyurea and Polyamide for Capacitive Energy Storage. Phys. Rev. B: Condens. Matter Mater. Phys. 2015, 92, 024203.

(17) Wu, S.; Li, W.; Lin, M.; Burlingame, Q.; Chen, Q.; Payzant, A.; Xiao, K.; Zhang, Q. M. Aromatic Polythiourea Dielectrics with Ultrahigh Breakdown Field Strength, Low Dielectric Loss, and High Electric Energy Density. Adv. Mater. 2013, 25, 1734-1738.

(18) Buckwalter, D. J.; Zhang, M.; Inglefield, D. L.; Moore, R. B.; Long, T. E. Synthesis and Characterization of Siloxane-Containing Poly(urea oxamide) Segmented Copolymers. Polymer 2013, 54, $4849-4857$.

(19) Thakur, Y.; Zhang, B.; Dong, R.; Lu, W.; Iacob, C.; Runt, J.; Bernholc, J.; Zhang, Q. M. Generating High Dielectric Constant Blends from Lower Dielectric Constant Dipolar Polymers Using Nanostructure Engineering. Nano Energy 2017, 32, 73-79.

(20) Wang, Y.; Zhou, X.; Lin, M.; Zhang, Q. M. High-Energy Density in Aromatic Polyurea Thin Films. Appl. Phys. Lett. 2009, 94, 202905.

(21) Mannodi-Kanakkithodi, A.; Treich, G. M.; Huan, T. D.; Ma, R.; Tefferi, M.; Cao, Y.; Sotzing, G. A.; Ramprasad, R. Rational CoDesign of Polymer Dielectrics for Energy Storage. Adv. Mater. 2016, $28,6277-6291$. 
(22) Sharma, V.; Wang, C.; Lorenzini, R. G.; Ma, R.; Zhu, Q.; Sinkovits, D. W.; Pilania, G.; Oganov, A. R.; Kumar, S.; Sotzing, G. A.; Boggs, S. A.; Ramprasad, R. Rational Design of All Organic Polymer Dielectric. Nat. Commun. 2014, 5, 4845.

(23) Kim, C.; Chandrasekaran, A.; Huan, T. D.; Das, D.; Ramprasad, R. Polymer Genome: A Data-Powered Polymer Informatics Platform for Property Predictions. J. Phys. Chem. C 2018, 122, 17575-17585.

(24) Sasada, Y.; Ichinoi, R.; Oyaizu, K.; Nishide, H. Supramolecular Organic Radical Gels Formed with 2,2,6,6-Tetramethylpiperidin-1oxyl-Substituted Cyclohexanediamines: A Very Efficient ChargeTransporting and -Storable Soft Material. Chem. Mater. 2017, 29, 5942-5947.

(25) Guo, J.; Liu, M.; Zehnder, A. T.; Zhao, J.; Narita, T.; Creton, C.; Hui, C.-Y. Fracture Mechanics of A Self-healing Hydrogel with Covalent and Physical Crosslinks: A Numerical Study. J. Mech. Phys. Solids 2018, 120, 79-95.

(26) Yanagisawa, Y.; Nan, Y.; Okuro, K.; Aida, T. Mechanically Robust, Readily Repairable Polymers via Tailored Noncovalent Crosslinking. Science 2018, 359, 72-76.

(27) Wu, S.; Lin, M.; Burlingame, Q.; Zhang, Q. M. Meta-aromatic polyurea with high dipole moment and dipole density for energy storage capacitors. Appl. Phys. Lett. 2014, 104, 072903.

(28) Lorenzini, R. G.; Kline, W. M.; Wang, C. C.; Ramprasad, R.; Sotzing, G. A. The rational design of polyurea \& polyurethane dielectric materials. Polymer 2013, 54, 3529-3533.

(29) Samant, S. P.; Grabowski, C. A.; Kisslinger, K.; Yager, K. G.; Yuan, G.; Satija, S. K.; Durstock, M. F.; Raghavan, D.; Karim, A. Directed Self-Assembly of Block Copolymers for High Breakdown Strength Polymer Film Capacitors. ACS Appl. Mater. Interfaces 2016, 8, 7966-7976.

(30) Tseng, J.-K.; Tang, S.; Zhou, Z.; Mackey, M.; Carr, J. M.; Mu, R.; Flandin, L.; Schuele, D. E.; Baer, E.; Zhu, L. Interfacial polarization and layer thickness effect on electrical insulation in multilayered polysulfone/poly(vinylidene fluoride) films. Polymer 2014, 55, 8-14. 